\title{
Effect of Ultrasonic Irradiation Conditions on Metal Surface during Multifunction Cavitation
}

\author{
Masataka Ijiri*, Toshihiko Yoshimura \\ Sanyo-Onoda City University, Sanyo-Onoda, Japan \\ Email: *ijiri@rs.tusy.ac.jp
}

How to cite this paper: Ijiri, M. and Yoshimura, T. (2018) Effect of Ultrasonic Irradiation Conditions on Metal Surface during Multifunction Cavitation. Materials Sciences and Applications, 9, 698-704. https://doi.org/10.4236/msa.2018.98050

Received: May 21, 2018

Accepted: July 8, 2018

Published: July 11, 2018

Copyright $\odot 2018$ by authors and Scientific Research Publishing Inc. This work is licensed under the Creative Commons Attribution International License (CC BY 4.0).

http://creativecommons.org/licenses/by/4.0/

\section{(c) (i) Open Access}

\begin{abstract}
Processing using multifunction cavitation (MFC) has recently enabled functional characteristics to be imparted to various materials. It is possible to process a material surface in the same manner as with conventional water jet (WJ) peening; however, the cavitation bubble temperature is different. To further improve this MFC technology, we examine the surface reforming of low alloy steel (JIS-SCM435) using MFC with various modes of ultrasonic waves. The ultrasonic equipment used for MFC processing includes dual, single, pulse and frequency modulation (FM) ultrasonic modes. Improvement of the residual stress and corrosion resistance was confirmed for all modes. The dual mode showed the maximum values of residual compressive stress and surface potential. The sound pressure at the machining spot was the highest with dual mode, and the temperature in the bubble generated by the WJ nozzle was highest and the amount of dissolved oxygen was lowest. Improvement of the residual stress and corrosion resistance was promoted because the temperature and pressure in the bubble interior during processing was higher than in the other modes.
\end{abstract}

\section{Keywords}

Multifunction Cavitation, Residual Stress, Corrosion Resistance, Ultrasonic, Water Jet Peening

\section{Introduction}

Peening is a technique used to improve the fatigue strength and the stress corrosion cracking resistance of metal parts, due to work hardening and plastic deformation of the surface layer by strong tapping of the material surface. Water jet peening (WJP) [1] [2] [3] [4] [5] is a peening method that utilizes the cavitation phenomenon, and it is applied for preventive maintenance [2] in nuclear 
power plants. It is possible to reduce the tensile residual stress generated in a structure by welding or machining. When the WJP technique is applied to a structure, stress corrosion cracking [1] and metal fatigue [1] [6] can be prevented.

Cavitation jets occur in the WJP process when high-pressure water containing fine microscopic cavitation bubbles is injected. Cavitation bubbles are repeatedly produced in a turbulent flow within the surrounding water and generate an extremely large impact force together with sound. The cavitation bubbles shrink at high speed due to the surrounding pressure, generate large shock waves and microjets, and then disappear. WJP is a processing method that induces a small amount of plastic deformation of a material surface by this impact pressure. When a minute portion on the material surface is stretched and plastically deformed, the deformed portion is elastically restrained from the surroundings, so that compressive residual stress is imparted to the impacted region. Therefore, when WJP is applied to a material surface where tensile residual stress remains, it is possible to change from tensile residual stress to compressive residual stress. However, when the residual stress is made compressive, it has been reported that voids and cracks tend to form inside the specimen due to the pressure increase applied to the surface with WJP [3] [4] [5].

Recently, Yoshimura et al. developed multifunction cavitation (MFC) [7] processing, which is a cavitation technique that applies ultrasonic waves to WJP. It is possible to reform a material surface with MFC in the same way as with WJP. However, the cavitation bubble temperature with MFC is different; the sound pressure due to ultrasonication exceeds the break threshold [7] [8] [9] after the bubbles from the WJ nozzle collide with the material surface. Therefore, high-temperature, high-pressure cavitation that produces hot spots occurs by repeated isothermal expansion and adiabatic compression. If a cavitation bubble begins to collapse when it is approaching the specimen surface, the volume of the bubble decreases, and a microjet is formed that impacts the surface of the object. The impact force is large because of the high temperature (several thousand degrees Celsius) and high pressure (about $1000 \mathrm{MPa}$ ) inside the bubble. Various properties of MFC-processed materials have been reported to date [4] [5] [7] [8] [9] [10].

Here, to further improve the MFC technique, we investigate the surface modification of low alloy steel (JIS-SCM 435) with MFC using different ultrasonic wave modes.

\section{Materials and Methods}

The material used for these tests was Cr-Mo steel (SCM435), which is a structural machine steel with the chemical composition shown in Table 1 . This alloy was made by Sanyo Special Steel Co., LTD. Round bar (rod) specimens were heated at $860^{\circ} \mathrm{C}$ as a solution treatment, followed by quenching. Tempering was performed at $600^{\circ} \mathrm{C}$. The specimens were subsequently cut into rectangular specimens with dimensions of $100 \times 100 \times 3 \mathrm{~mm}$. 
Figure 1 shows the MFC processing equipment, in which an ultrasonic transducer (WD-1200-28T, Honda Electronics Co., Ltd.) irradiates the water jet as it emerges from the nozzle. A swirl flow nozzle [11] was used at the tip of the WJ nozzle to increase the number and size of cavitation bubbles. The discharge pressure of the pump was about $35 \mathrm{MPa}$, the nozzle diameter was $0.8 \mathrm{~mm}$, and the distance between the nozzle and the specimen was assumed to be $65 \mathrm{~mm}$, which is considered as the second peak [12] with the highest cavitation-bubble density. Processing was performed in a tank (JIS-SUS310S) with dimensions of $41 \times 44 \times 60 \mathrm{~cm}$. The output of the ultrasonic transducer was $1200 \mathrm{~W}$ and the nominal drive frequency was $28 \mathrm{kHz}$. This device has dual, single, pulse and frequency modulation (FM) ultrasonic modes, and all waveforms are sinusoidal. Dual mode switches between $25 \mathrm{kHz}$ and $27 \mathrm{kHz}$ every $10 \mathrm{~Hz}$. The single-mode output is constant at $26 \mathrm{kHz}$. Pulse mode toggles between 26 and $26.5 \mathrm{kHz}$ every $5 \mathrm{~Hz}$. FM randomly switches between 25 and $27 \mathrm{kHz}$ every $10 \mathrm{~Hz}$. All processing times were 2 min.

Residual stress was measured using an X-ray stress analyzer (MSF-3M, Rigaku Co., Ltd.) with the peak top method after measurement of the (211) strain between lattice planes with the $\mathrm{Cr} \mathrm{Ka}$ line generated at $30 \mathrm{kV}-10 \mathrm{~mA}$. A region of 1 $\times 1 \mathrm{~cm}$ was measured. Tensile residual stress was taken to be positive and compressive residual stress was taken to be negative. The sound pressure was measured

Table 1. Chemical composition of SCM435.

\begin{tabular}{cccccccccc}
\hline & & & & & & & & (mass \%) \\
\hline $\mathrm{C}$ & $\mathrm{Si}$ & $\mathrm{Mn}$ & $\mathrm{P}$ & $\mathrm{Ni}$ & $\mathrm{Cr}$ & $\mathrm{Mo}$ & $\mathrm{Cu}$ & $\mathrm{Fe}$ \\
0.37 & 0.32 & 0.81 & 0.014 & 0.012 & 0.95 & 0.15 & 0.14 & $\mathrm{Bal}$. \\
\hline
\end{tabular}

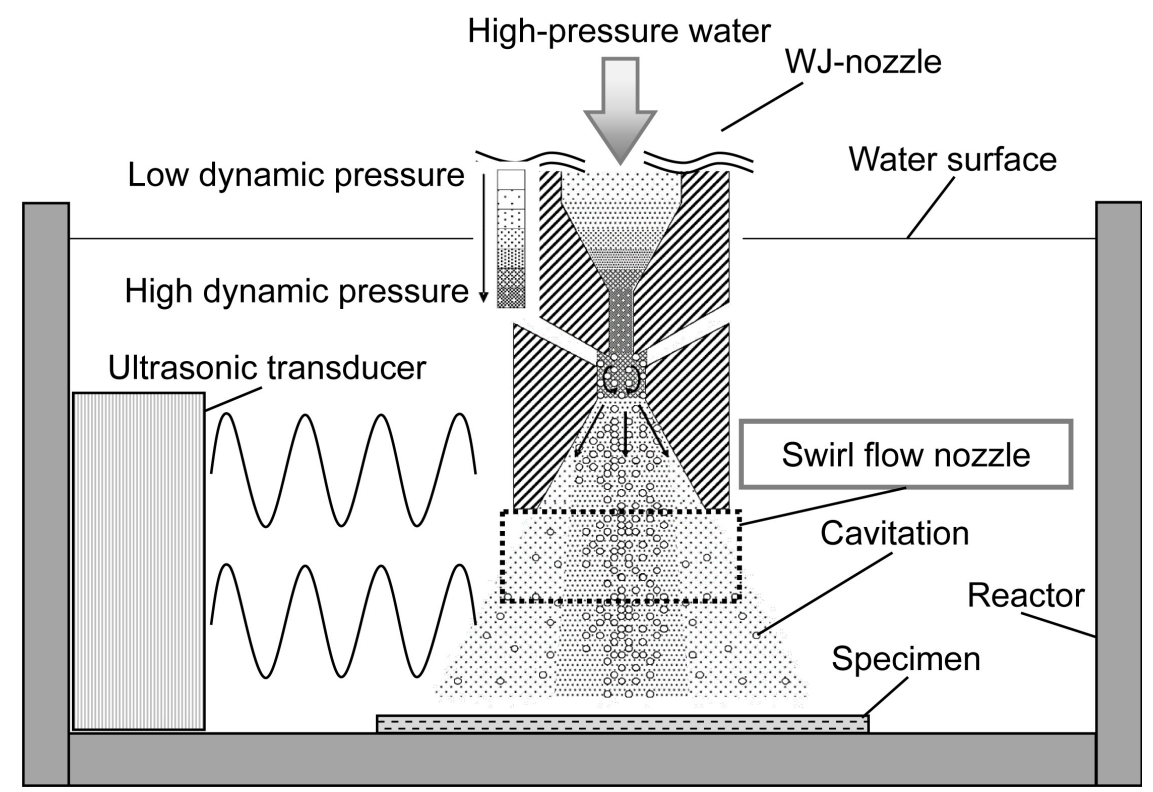

Figure 1. MFC processing equipment for surface machining by WJ cavitation under ultrasonication. 
with a sonic monitor (HUS-5 SUS, Honda Electronics Co., Ltd.). The corrosion resistance was evaluated by measuring the surface potential using a Kelvin probe force microscopy (KFM) system equipped with a multi-compatible miniature probe microscope (AFM5200S Hitachi High-Tech Sciences Co., Ltd.). The measurement area was $100 \times 100 \mu \mathrm{m}$, and the value obtained by subtracting three lines by line analysis was averaged. The amount of dissolved oxygen (DO) in the water where cavitation occurred was measured $30 \mathrm{~min}$ after cavitation had begun using a portable dissolved oxygen meter (OM-71, Horiba, Ltd.).

\section{Results and Discussion}

Table 2 shows the results of residual stress measurements. In the unprocessed material, tensile residual stress was found in the grinding direction and compressive residual stress was found in the vertical direction. Residual stress measurements after various types of processing were performed in the grinding direction. For all specimens, the tensile residual stress was converted to compressive residual stress. Dual mode produced the maximum residual stress, and the FM mode produced the minimum. Thus, the residual stress was significantly affected by the ultrasonic wave mode.

The relative sound pressure (expressed as a voltage) of the ultrasonic waves for each mode was measured at the WJ nozzle position (about $45 \mathrm{~mm}$ from the ultrasonic transducer): for pulse mode it was $8-9.5 \mathrm{mV}$, for single mode it was $11-13 \mathrm{mV}$, for FM mode it was $10-12 \mathrm{mV}$, and for dual mode it was $14-16$ $\mathrm{mV}$. The highest sound pressure was obtained with dual mode. The bubbles generated by the WJ that received this sound pressure had hot spots, which is considered to be why the largest residual compressive stress was produced. This hot spot phenomenon makes it very difficult to measure the temperature inside the bubble.

The oxide film formed on the specimen surface after each MFC process was measured using KFM to confirm the increase of the specimen surface temperature, as shown in Table 3. KFM detects the displacement of a cantilever due to an electrostatic attractive force on the specimen surface; therefore, it is possible to obtain the work function difference (contact potential difference) between the

Table 2. Residual stress in specimens after various treatments.

\begin{tabular}{|c|c|c|c|}
\hline & & $\begin{array}{c}\text { Half value } \\
\text { breadth method }(\mathrm{MPa})\end{array}$ & $\begin{array}{l}\text { Peak top method } \\
\qquad(\mathrm{MPa})\end{array}$ \\
\hline \multirow{2}{*}{$\begin{array}{l}\text { As-received after } \\
\text { grinding }\end{array}$} & Parallel direction & +202.04 & +179.70 \\
\hline & Vertical direction & -173.34 & -158.50 \\
\hline \multicolumn{2}{|c|}{ MFC (Single) } & -327.59 & -336.71 \\
\hline \multicolumn{2}{|c|}{ MFC (Pulse) } & -407.84 & -397.36 \\
\hline \multicolumn{2}{|c|}{$\operatorname{MFC}(\mathrm{FM})$} & -319.27 & -309.45 \\
\hline \multicolumn{2}{|c|}{ MFC (Dual) } & -439.54 & -399.96 \\
\hline
\end{tabular}


probe and the specimen surface. The electrostatic force received by the probe from the fixed charge distributed on the specimen surface is detected to obtain the surface potential. Surface potential measurements are significantly affected by surface roughness; therefore, the specimen surfaces were polished to a mirror finish before MFC processing. The surface potential for the specimens processed under the various modes all increased relative to that for the unprocessed material, with dual mode showing the highest value. The increase in surface potential is reported to be due to selective oxidation during MFC processing, so that an oxide film is likely to be formed on the specimen surface [10].

To clarify the cause of surface oxidation, Figure 2 shows the results for water temperature and dissolved oxygen concentration in the water tank for each processing mode. Since both the water temperature and the dissolved oxygen concentration varied initially, the measurements were performed after 30 minutes of processing to ensure stable values. The water temperature before processing was about $11^{\circ} \mathrm{C}-15^{\circ} \mathrm{C}$ and the dissolved oxygen amount was about $11-12 \mathrm{mg} / \mathrm{L}$. As a result of processing for $30 \mathrm{~min}$, the water temperature increased and the dissolved oxygen concentration decreased. Almost no difference in water temperature was observed for the different ultrasonic modes. However, the decrease in the amount of dissolved oxygen was smallest in FM mode and largest in dual mode. These results indicate that alternating the frequency between $25 \mathrm{kHz}$ and $27 \mathrm{kHz}$ every $10 \mathrm{~Hz}$ as in dual mode generates high temperature and high pressure

Table 3. Surface potential for specimens after various MFC treatment for $2 \mathrm{~min}$.

\begin{tabular}{cc}
\hline & Surface potential \\
\hline Mirror-finished specimen & $234 \pm 14 \mathrm{mV}$ \\
MFC (Single) & $439 \pm 19 \mathrm{mV}$ \\
MFC (Pulse) & $408 \pm 19 \mathrm{mV}$ \\
MFC (FM) & $428 \pm 20 \mathrm{mV}$ \\
MFC (Dual) & $542 \pm 13 \mathrm{mV}$ \\
\hline
\end{tabular}

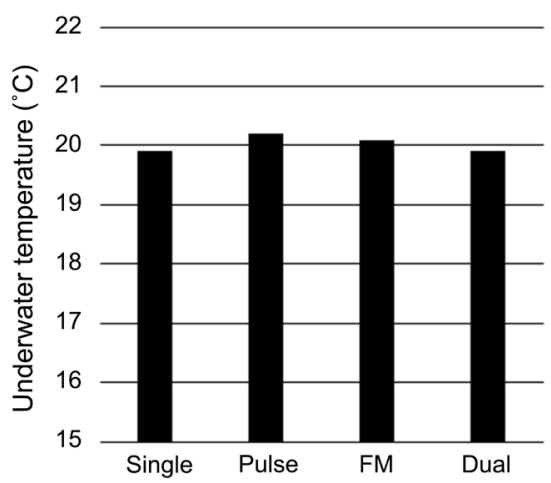

(a)

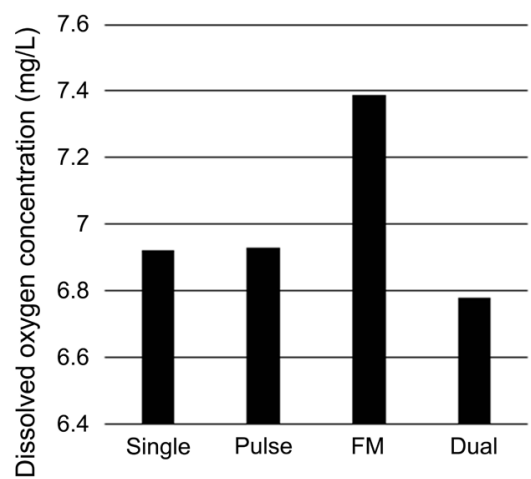

(b)

Figure 2. (a) Underwater temperature; and (b) Amount of dissolved oxygen for different ultrasonic conditions. 
in the bubbles during processing. However, the cause of this phenomenon has yet to be clarified. In addition, besides the frequency change of the ultrasonic waves, the reactor which reflects the ultrasonic waves also influences the temperature and pressure inside the bubbles. It has been reported that the resonance conditions for a reactor depends on the water surface height and the water temperature, even if the frequency is constant [13]. Therefore, it will be necessary to further consider such factors in future work.

\section{Conclusion}

Improvement of residual stress and corrosion resistance was confirmed for all ultrasonic wave modes in MFC processing of Cr-Mo steel; however, dual mode showed the maximum values. In dual mode, the sound pressure at the machining spot was the highest, so that the temperature inside the bubbles from the WJ nozzle was the highest, and the amount of dissolved oxygen was the lowest. As a result, improvement of the residual stress and corrosion resistance was promoted because of the high-temperature and high-pressure in the bubble interior during processing.

\section{Acknowledgements}

This work was supported by the "Innovative Science and Technology Initiative for Security" program of the Acquisition, Technology \& Logistics Agency (ATLA) of Japan.

\section{References}

[1] Hirano, K., Enomoto, K., Hayashi, E. and Kurosawa, K. (1996) Effects of Water Jet Peening on Corrosion Resistance and Fatigue Strength of Type 304 Stainless Steel. Journal of the Society of Materials Science, 45, 740-745. https://doi.org/10.2472/jsms.45.740

[2] Saitou, N., Enomoto, K., Kurosawa, K., Morinaka, R., Hayashi, E., Ishikawa, T. and Yoshimura, T. (2003) Development of Water Jet Peening Technique for Reactor Internal Components of Nuclear Power Plant. Journal of Jet Flow Engineering, 20, $4-12$.

[3] Ijiri, M., Shimonishi, D., Nakagawa, D. and Yoshimura, T. (2017) Evolution of Microstructure from the Surface to The interior of Cr-Mo Steel by Water Jet Peening. Materials Sciences and Applications, 8, 708-715. https://doi.org/10.4236/msa.2017.810050

[4] Ijiri, M. and Yoshimura, T. (2018) Evolution of Surface to Interior Microstructure of SCM435 Steel after Ultra-High-Temperature and Ultra-High-Pressure Cavitation Processing. Journal of Materials Processing Technology, 251, 160-167. https://doi.org/10.1016/j.jmatprotec.2017.08.016

[5] Ijiri, M., Shimonishi, D., Nakagawa, D., Tanaka, K. and Yoshimura, T. (2017) Surface Modification of Ni-Cr-Mo Steel by Multifunction Cavitation. Journal of Materials Science and Engineering A, 7, 290-296.

[6] Odhiambo, D. and Soyama, H. (2003) Cavitation Shotless Peening for Improvement of Fatigue Strength of Carbonized Steel. International Journal of Fatigue, 25, 1217-1222. https://doi.org/10.1016/S0142-1123(03)00121-X 
[7] Yoshimura, T., Tanaka, K. and Yoshinaga, N. (2016) Development of Mechanical-Electrochemical Cavitation Technology. Journal of Jet Flow Engineering, 32, 10-17.

[8] Yoshimura, T., Tanaka, K. and Yoshinaga, N. (2018) Nano-Level Material Processing by Multifunction Cavitation. Nanoscience \& Nanotechnology-Asia, 8, 41-54. https://doi.org/10.2174/2210681206666160922164202

[9] Yoshimura, T., Tanaka, K. and Yoshinaga, N. (2016) Material Processing by Mechanical-Electrochemical Cavitation. BHR Group, Hartford, 223-235.

[10] Ijiri, M. and Yoshimura, T. (2018) Improvement of Corrosion Resistance of Low-Alloy Steels by Resurfacing Using Multifunction Cavitation in Water. IOP Conference Series: Materials Science and Engineering, 307, Article ID: 012040. https://doi.org/10.1088/1757-899X/307/1/012040

[11] Ijiri, M., Shimonishi, D., Nakagawa, D. and Yoshimura, T. (2018) New Water Jet Cavitation Technology to Increase Number and Size of Cavitation Bubbles and Its Effect on Pure Al Surface. International Journal of Lightweight Materials and Manufacture, 1, 12-20. https://doi.org/10.1016/j.ijlmm.2018.03.003

[12] Yamauchi, Y., Soyama, H., Sato, K., Ikohagi, T. and Oba, R. (1994) Development of Erosion in High-Speed Submerged Water Jets. Transactions of the Japan Society of Mechanical Engineers, Series B, 60, 736-743. https://doi.org/10.1299/kikaib.60.736

[13] Nomura, S., Murakami, K. and Sasaki, Y. (2000) Streaming Induced by Ultrasonic Vibration in a Water Vessel. Japanese Journal of Applied Physics, 39, 3636-3640. https://doi.org/10.1143/JJAP.39.3636 